\title{
Familial Contributions to the Etiology and Course of Anorexia Nervosa and Bulimia
}

\author{
Michael Strober \\ Neuropsychiatric Institute, School of Medicine \\ University of California, Los Angeles
}

\author{
Laura Lynn Humphrey \\ Department of Psychiatry \\ Northwestern University Medical School
}

\begin{abstract}
In this article, we summarize the current knowledge of familial influences in anorexia nervosa and bulimia. Three lines of evidence are reviewed: descriptions of family interaction, familial correlates of the course and phenomenology of symptoms, and studies of familial transmission. We conclude that although certain familial patterns are associated with eating disorders, there is no single mechanism or pathway of influence. Rather, it seems likely that certain personality factors, which may be genetically determined, predispose the individual to greater sensitivity and vulnerability to powerful familial and social experiences that impinge adversely on self-esteem and self-efficacy.
\end{abstract}

Although the role played by familial factors in the etiology of eating disorders currently excites a great deal of theoretical interest, empirical data are fragmentary, and most ideas about the nature and extent of this role are highly speculative (Kog \& Vandereycken, 1985; Yager \& Strober, 1985). In this article, we review evidence on the familial factors that have been linked to the development and course of anorexia nervosa and bulimia. We do not imply that these factors are the most influential determinants of vulnerability to the eating disorders; rather, we believe that a detailed account of the potential advances and the methodological problems that hamper ongoing efforts in this area is timely.

\section{Descriptive Studies}

Early descriptions of family-wide distress in eating disorders were rich and compelling accounts of how the parents of anorexics responded to the crisis of their child's starvation and of the role played by the illness in family dynamics (see reviews by Bemis, 1978; Garfinkel \& Garner, 1982). Mothers of anorexics were commonly described as intrusive, overprotective, anxious, perfectionistic, and fearful of separating from their children; fathers were commonly described as emotionally constricted, obsessional, moody, withdrawn, passive, and ineffectual. Generally, the theoretical accounts from both psychodynamic and family-systems perspectives converge to describe the anorexic as one who has difficulty separating from the family and consolidating a separate, individuated identity (e.g., Bruch, 1973; Minuchin, Rosman, \& Baker, 1978). Problems in individuation were thought to result, in large part, from broader and more pervasive disturbances in family dynamics, role structure, and affective expression among family members.

The most well-developed description was formulated by Mi-

Correspondence concerning this article should be addressed to $\mathrm{Mi}$ chael Strober, Neuropsychiatric Institute, School of Medicine, University of California, Los Angeles, 760 Westwood Plaza, Los Angeles, California 90024 . nuchin et al. (1978), who hypothesized that the anorexic's psychologically and physically regressive state preserves a tenuous harmony and closeness within the family, albeit at great personal cost, by diverting attention away from the parents' vulnerabilities and marital strains. Based on their observations of nearly 60 families, Minuchin et al. identified five primary patterns of impaired interaction that they believed lay at the core of psychosomatic pathologies: enmeshment, overprotectiveness, rigidity, conflict avoidance, and poor conflict resolution. In essence, symptomatic behavior and family processes were viewed systemically as being bound together in a self-regulating cycle that minimized conflict and change.

By contrast, little attention has been given historically to the familial underpinnings and correlates of bulimia. Recently, however, Humphrey (1986a, in press) has reported on a series of well-controlled studies that suggest that the binge-purge cycle itself provides an apt metaphor for pervasive and chronically recurring family-wide deficits and excesses. Just as the bulimic periodically craves food during a binge, so do she and her family repeatedly crave and attempt to solicit nurturance, soothing, and empathy from one another. Similarly, family members are thought to purge themselves by expelling their aggression and frustration toward one another without structure, focus, or resolution. In a more psychodynamic vein, Humphrey and Stern (in press) postulated that although bulimic and anorexic families exhibit features in common, the bulimic more often assumes the projection of the "bad," inadequate, and split-off parts of the parents' personalities. Such a pattern enables the parents to preserve a semblance of well-being at the same time it maintains family-wide homeostasis by diverting attention away from deeply rooted areas of dissatisfaction and conflict.

The extant empirical data on individual psychopathology in parents, parent-child relationships, and family interaction patterns lend some support to these formulations. Several retrospective and/or uncontrolled studies have suggested that psychological disturbance of varying intensity is present in at least some parents of anorexics (Beumont, Abraham, Argall, George, \& Glaun, 1978; Kalucy, Crisp, \& Harding, 1977) and that it often antedates the onset of the child's symptoms (Crisp, 
Hsu, Harding, \& Hartshorn, 1980; Morgan \& Russell, 1975). On the other hand, a study by Garfinkel et al. (1983) failed to show significant differences between parents of anorexics and parents of normal control subjects on various measures of depression and personality functioning.

Several recent studies have used self-report indices to compare perceived family relationships among anorexic or bulimic family members with those of normal control subjects. Three independent projects have found replicable differences between bulimics and normal control subjects on the Family Environment Scale (Moos \& Moos, 1980) and on the Family Adaptability and Cohesion Evaluation Scale (Olson, Bell, \& Portner, 1978). Both Johnson and Flach (1985) and Ordman and Kirschenbaum (1986) found that bulimics perceived their families as less cohesive, expressive, and active in recreation and as more conflictual when compared with the perceptions of normal women. Using these same measures, Humphrey (1986b) found that bulimic-anorexic family members perceived their relationships as less involved and supportive and as more isolated, conflictual, understructured, and detached than did control subjects. In a related project, Humphrey (in press) used a self-report measure developed by Benjamin (1974) to quantitate indicators of affiliation-disaffiliation and independence-interdependence among family members and found that bulimicanorexic patients and their parents perceived each other as more belittling, attacking, and neglectful and as less trusting, nurturing, and disclosing toward one another compared with normal families. Similarly, Garfinkel et al. (1983) showed that anorexics and their mothers perceived the family as having greater difficulty with task accomplishment, role performance, communication, and affective expression compared with normal control families.

To date, there are few laboratory studies of family interaction in anorexia nervosa or bulimia. Goldstein (1981) used verbatim transcripts of parental Thematic Apperception Test responses and videotaped interactions of the family during a problemsolving task to rate communication deviance (ambiguous or illogical statements), negative affective style (critical, intrusive, or guilt-inducing statements), and dependency-insecurity in the families of 11 hospitalized anorexics, 5 nonanorexic hospitalized psychiatric control subjects, and 52 nonanorexic outpatient psychiatric control subjects. Anorexic families differed most significantly from control families on the measure of dependency-insecurity (solicitation of support and protection, tentativeness of response, and compliancy), which was interpreted by Goldstein (1981) to signify a lesser tolerance for conflict and for the expression of negative emotional states.

More recently, Humphrey (1987; Humphrey, Apple, \& Kirschenbaum, 1986) compared the families of bulimic anorexics with normal control families using Benjamin's (1974) structural analysis of social behavior model (SASB). Participants were asked to discuss an aspect of their daughter's separation from the family, and interactions were videotaped and coded by trained observers. The findings were quite consistent with those from the parallel rating scales in showing that families of bulimic anorexics were more belittling, neglectful, and walled-off compared with normal control subjects and were less helpful, trusting, and nurturing toward each other. The parents of bulimics were also shown to use more double-bind communica- tions that juxtaposed the opposing directives of taking control and of giving autonomy to their daughters, whereas bulimicanorexic daughters displayed greater ambivalence in interactions with their parents and often fluctuated between resentful submission and active assertion compared with normal control subjects.

A recent study by Kog, Vandereycken, and Vertommen (1985), though uncontrolled and based on a small, clinically heterogenous sample, deserves special mention as the first attempt to operationalize Minuchin's constructs (enmeshment, rigidity, overprotectiveness, and conflict avoidance) from the responses of family members to a series of problem-solving tasks. An unexpected finding showed that the behavior of these families was highly variable; though enmeshment was common, evidence for the other hypothesized patterns was weak, which suggests the need to examine heterogeneity within this population if pathogenic familial influences are to be identified more precisely.

To summarize, descriptive studies have suggested that dysfunctional family relationships, often accompanied by signs of individual psychopathology in parents, appear frequently in association with the development and persistence of eating disorders. Bulimics and bulimic anorexics as well as (to a certain degree) their parents perceive their family environments as more conflictual and disengaged and as less cohesive and nurturant than normal control subjects. Likewise, studies of family interaction in the laboratory have suggested that bulimic and anorexic families are enmeshed, intrusive, hostile, and negating of the child's emotional needs. Exactly how these phenomena facilitate or potentiate weight concern and dieting behavior remains unexplained. There are, of course, limitations in these studies that deserve mention. Because the data were cross-sectional, any inferences regarding causation are tentative at best. There is little evidence at present as to (a) whether these patterns are distinctly different from those operating in other conditions; (b) whether they are stable over time; (c) how they are influenced (if at all) by remissions or exacerbations of the patient's symptoms; and (d) what proportion of the variance in predisposition is accounted for if their association with eating disorders indeed reflects a causal effect.

\section{Familial Influences on Illness Course and Clinical Heterogeneity}

Because morbidity and mortality in anorexia nervosa are high, the identification of robust predictors of the course and outcome of the illness has obvious practical and theoretical significance. Several studies (Crisp, Harding, \& McGuiness, 1974; Hsu, Crisp, \& Harding, 1979; Morgan \& Russell, 1975; Szmukler, Eisler, Russell, \& Dare, 1985) have associated greater severity of family disturbance (broadly defined) with a poorer overall prognosis and with premature termination of treatment. We may infer from these data that particularly long-standing and adverse family problems (e.g., chronic discord, extreme alienation of affection, extreme restriction of autonomy) increase risk to the patient of a more chronic course of illness, although the possibility that nonfamilial variables may predict illness course at least as accurately cannot be overlooked.

Another fruitful avenue of descriptive investigation in recent 
years has examined familial differences between clinical subtypes of the illness. Beyond its implications for developing more valid family and diagnostic typologies, this work has added greatly to our understanding of how familial factors shape the phenomenology of eating disorders.

We are aware of six studies that have compared perceptions of the family environment (Garner, Garfinkel, \& O'Shaughnessy, 1985; Humphrey, 1986d, 1986e; Kog, Vertommen, \& De Groote, 1986; Strober, 1981) or have observed family interaction (Humphrey, 1986c) in the bulimic and restricting subtypes of eating disorders. With one exception (Kog et al., 1986), the findings converge in their portrayal of the intrafamilial environments of bulimics and bulimic anorexics as more hostile, conflictual, isolative, depriving, and disorganized and as less nurturant, supportive, and understanding than the family environments of restricting anorexics. Strober, Salkin, Burroughs, and Morrell (1982) also compared the Minnesota Multiphasic Personality Inventory (MMPI) profiles from 35 parents of bulimic anorexics with those of 35 parents of restricting anorexics and found the parents of the bulimic subgroup to be significantly more hostile, impulsive, and excitable than the parents of the restricting subgroup. Humphrey (1986c, 1986d, 1986e) has compared these three subtypes of eating disorders with one another and with normal control subjects and has found that, whereas all three clinical groups perceived their relationships as more blaming, rejecting, and neglectful relative to control subjects, only the two bulimic subgroups also perceived a deficit in parental nurturance and empathy (Humphrey, 1986e). Compared with the families of restricting anorexics, the families of bulimics were more hostilely enmeshed and deficient in affection and support, whereas the families of restricting anorexics more frequently juxtaposed opposing messages of affection and caring with enmeshment and negation of the child's needs.

The evidence to date has also suggested that bulimic and nonbulimic subtypes may differ in rates of familial psychiatric disorder (alcoholism, in particular), although proper controlled studies are scarce. Strober et al. (1982) found a fourfold greater rate of alcoholism in the first-degree relatives of bulimic anorexics than in the relatives of restricting anorexics (16\% vs. $4 \%, p$ $<.02$ ). A significantly higher prevalence of alcoholism in the relatives of bulimics and bulimic anorexics than in the relatives of restricting anorexics has been documented by other investigators (Hudson, Pope, Jonas, \& Yurgelun-Todd, 1983; Piran, Kennedy, Garfinkel, \& Owens, 1985).

One last distinction of potential importance concerns the prevalence of parental obesity, which has been found in several studies (Garfinkel, Moldofsky, \& Garner, 1980; Garner et al., 1985; Herzog, 1982; Strober, 1981) to be moderately to significantly higher in bulimic anorexics than in restricting anorexics.

In sum, accumulating evidence suggests that there are distinctively different patterns of family interaction, psychopathology, and body-weight tendencies between bulimic and nonbulimic subtypes. Bulimia has been strongly associated with a lack of parental affection; overly negative, hostile, and disengaged patterns of family interaction; increased parental impulsivity and familial alcoholism; and increased familial obesity. Despite the hazards of inferring causal effects from these associations, several alternative explanations may be considered. First, bulimia may be mediated in part through deficits in self-efficacy and self-regulation stemming from an inadequate and adverse family environment (rejection, hostility, impulsivity, discord, etc.). Such an environment may result in behavioral deficits in coping and feelings of being overwhelmed by painful and disruptive affective states. These vulnerabilities, in the context of pressures to diet and to maintain a low body weight, may lead to periodic episodes of dysregulation (binge eating) followed by self-reproach and efforts to purge the ingested food. Second, bulimia may also reflect (at least in some patients) an unfuifilled craving for nurturance and a remedy for intensely painful feelings of rejection and loneliness. A third possibility is that innate tendencies toward impulsivity may disrupt efforts at strict dietary control and may thus increase the likelihood of periodic overeating. Finally, the association between bulimia and parental obesity suggests that there may be a greater constitutional resistance to weight loss in certain individuals that is causally related to binge eating under conditions of nutrient deprivation.

\section{Familial Transmission}

A further compelling indication of familial involvement in the pathogenesis of the eating disorders comes from evidence that such disorders occur more frequently in the biological relatives of patients (current epidemiological data put the lifetime expectancy of anorexia nervosa at $0.5 \%-1.5 \%$ and of bulimia, at roughly $2.0 \%$; Cooper \& Fairburn, 1983; Crisp, Palmer, \& Kalucy, 1976; Gershon et al., 1983). In several studies (Dally \& Gomez, 1979; Garfinkel et al., 1980; Halmi, Goldberg, Eckert, Casper, \& Davis, 1977; Theander, 1970), the prevalence of anorexia nervosa among the sisters of patients has ranged from $3 \%$ to $10 \%$, which greatly exceeds rates in the general population. Crisp et al. (1980) reported a family history of probable anorexia nervosa (definitional criteria unspecified) to have been present in 29\% of 102 cases, whereas Kalucy, Crisp, and Harding (1977) reported a history of low adolescent weight and peculiar dietary habits, anorexia nervosa, or severe weight phobia in $27 \%$ of the mothers and in $16 \%$ of the fathers of 56 cases. In other studies (Hall, 1978; Hudson et al., 1983), the proportion of patients with positive family histories has ranged from $4 \%$ to $7 \%$, and the estimated prevalence in first-degree relatives has ranged from $4 \%$ to $6 \%$. Likewise, a recent twins study of anorexia nervosa (Holland, Hall, Murray, Russell, \& Crisp, 1984) showed that concordant cases were significantly overrepresented in monozygotic twin pairs, which may suggest some degree of genetic predisposition in individual cases.

Increased familial prevalence has also been found in larger studies that have used more systematic approaches to interview and diagnose relatives and have compared familial rates of the disorder with rates found in the relatives of matched control subjects. In a study of 99 first-degree relatives of 24 anorexic patients and of 265 relatives of normal control subjects, Gershon et al. (1983) found the lifetime risk of eating disorder in relatives of anorexics to be $6 \%$, compared with a $1 \%$ risk for relatives of control subjects. Similarly, Strober, Morrell, Burroughs, Salkin, and Jacobs (1985) found either definite or probable eating disorders in at least 1 first- or second-degree relative in $27 \%$ of anorexic patients, compared with only $6 \%$ in those of nonanorexic psychiatric control subjects. The pooled risk of eating disorder was 7 times as great among female first-degree 
relatives of anorexics than among female relatives of control subjects.

Other family studies have approached the question of familial transmission from the hypothesis that eating disorders and affective disorders are variants of a common, underlying etiology. With some exceptions (Stern et al., 1984; Theander, 1970), recent diagnostic studies have shown that affective disorders are overrepresented in the families of anorexic and bulimic patients. Unipolar depression has been shown to occur 2-4 times more frequently in the first-degree relatives of both anorexic and bulimic patients than in the general population (Gershon et al., 1983; Hudson et al., 1983; Rivinus et al., 1984; Strober et al., 1982; Winokur, March, \& Mendels, 1980), although the findings on bipolar illness are contradictory: Some studies support an increased risk of this illness among relatives of anorexics (Gershon et al., 1983; Winokur et al., 1980), whereas others (Rivinus et al., 1984; Strober et al., 1982; Strober et al., 1986) dispute a significant link.

Also unresolved is the question of whether individual differences among eating-disorder patients in the presence and severity of depressive symptoms accounts for significant variation in familial affective morbidity. Two studies (Biederman et al., 1985; Strober et al., 1986) have found increased rates of affective disorder only in relatives of a subset of anorexics with concurrent major depression, whereas another study (Gershon et al., 1984) found equally high rates among relatives of depressed and nondepressed anorexic patients. Hence, though data are limited, they do suggest the possibility that familial and genetic influences on the transmission of affective disorder may be distinctly greater in certain subgroups of eating-disorder patients (in particular, patients with coexisting affective disorder) and may be largely absent in others.

However, familial correlations with affective disorder do not necessarily warrant causal interpretations. To argue that eating disorders and affective disorders are genetically related, it must also be shown that eating disorders are overrepresented in the families of unipolar and bipolar affective-disorder patients. To our knowledge, only one study has examined the cross-prevalence of these disorders, and the results did not support the genetic variant hypothesis. In a large study in which all first-degree relatives were interviewed directly and diagnosed blindly, Strober et al. (1986) found that rates of eating disorder among relatives of schizophrenic, unipolar, and bipolar patients were uniformly low $(0.6 \%-1.3 \%)$ and were not any higher than their expected lifetime prevalence in the general population. The rate of eating disorders was greatest among the female relatives of anorexics $(10.3 \%)$, whereas the rate of affective disorders was greatest among the relatives of unipolar and bipolar patients. However, nearly 4 times as many cases of affective disorder were found among relatives of anorexics with concurrent major depression (diagnosed if symptoms of major depression persisted following refeeding) than among relatives of nondepressed anorexics who, as a group, were not found to be at any greater risk for affective disorder than persons in the general population.

Overall, such findings indicate that the transmission of affective disorders and eating disorders occurs along independent family lines. Whether the same is true of bulimia and affective disorders is unknown. Possible interactions among genetic, sociopsychological, and pathophysiologic processes that might ac- count for the coincidence of depression and eating disorder within individuals and families has been discussed in greater detail elsewhere (Strober \& Katz, in press).

In sum, though we must again stress the limited scope of the data, it seems clear that eating disorders (anorexia nervosa in particular) run in families. This increase in resemblance among relatives is obviously not a result of the direct modeling of symptoms because a positive family history was found in only a minority of patients. Nor do the data imply in any straightforward way that eating disorders are heritable. However, genetic effects may increase the likelihood that anorexia nervosa "breeds true" through their determination of personality traits (e.g., neuroticism, obsessive worrying and rigidity, introversion) that express themselves at puberty in the form of low self-esteem and maturity fears, which are known to increase the risk for developing eating disorders (Crisp, 1980; Strober, 1985). Thus, the contribution made by additive genetic factors to the familial prevalence of eating disorders is clearly nonspecific. On the other hand, the concentration of eating disorders in families may have nongenetic origins. This explanation gives greater emphasis to the powerful role played by the home environment in shaping both adaptive and deviant patterns of self-esteem, identity, and coping behavior.

Multiple cases of the disorder within individual kinships may stem from the cultural transmission of deviant family patterns across successive generations. Yet, very few relatives of eatingdisorder patients are themselves affected, despite sharing similar environments. Considering this point, and bearing in mind the complex, multiply determined nature of these conditions, we agree with Crisp (1985) that a plausible explanation of the familial data is one that considers how individual variations in genetic makeup interact with the environment in which personal vulnerability is expressed. As Crisp wrote,

A young child's natural dependency and undifferentiated charac-
teristics may be enhanced by overprotective family attitudes .
and excessive rewarding of compliant behavior. The potential for
avoidance behavior in the child may be reinforced as natural fear-
fulness of the outside world by the parents' own enmeshed relation-
ship and their associated fear of outside influences. This latter fear
will be much enhanced in them as well as in their child when she/he
reaches adolescence, begins to interact with the culture, discovers
sexuality as the new interpersonal currency, and challenges their
adjustments afresh. (Crisp, 1985, p. 9)

Thus, the predisposition to eating disorders may well originate in genetically influenced variations in personality and temperament, but their ultimate expression requires the added presence of disturbances in family interactions and in other sociocultural pressures.

\section{Conclusion}

It is not surprising that in a relatively new field of research, preliminary data raise almost as many questions as they answer. Nevertheless, several points have emerged from the work published to date that provide a framework for further theorizing and investigation. First, the family environment to which anorexic and bulimic patients are exposed appears to hamper the development of a stable identity, of autonomy, and of self-efficacy through a cluster of disturbed patterns of relating and in- 
teracting that are characterized by enmeshment, poor conflict resolution, emotional overinvolvement or detachment, and a lack of affection and empathy. Clinical experience and research have shown that such phenomena are not transitory; they often persist long after the patient's acute symptoms have subsided and, in some families, seem quite refractory to change. Second, it appears that a variety of family-related factors shape the phenomenology of the eating disorders (particularly bulimia). These factors seem to exert their influence through a number of constitutional and experiential pathways, including poor selfregulation of affect and behavior, tendencies toward alcoholism and obesity, and family-wide discord and emotional deprivation. Finally, there is increasingly persuasive evidence that eating disorders aggregate in families, although the genetic and environmental contributions to transmission have not yet been elucidated.

To exploit these leads fully, researchers will need to move beyond single, cross-sectional descriptions of clinical populations to consider how individual differences among patients covary with familial measures in illness duration, age at onset, associated psychopathology, and chronicity of symptoms and to consider how familial dynamics change (if at all) over time.

Second, researchers should use a range of objective self-report and observational instruments for measuring the components of family interaction (e.g., role hierarchies, conflict, communication style) within different settings (e.g., within the laboratory, in treatment, at home) to establish the generality and concurrent validity of these measurements.

Third, follow-up studies are needed that use the techniques of multivariate regression analysis to assess the differential power of familial and nonfamilial variables in predicting course and outcome.

Fourth, in relation to the findings on family transmission, researchers must investigate whether patients whose eating disorder runs in the family exhibit markedly different family backgrounds. Parallel investigations might examine the presence versus absence of a family history of affective disorders. If the discriminating power of family history proves high, such a strategy may elucidate risk factors associated with a greatly increased susceptibility to eating disorders.

In closing, it is important to emphasize that if anorexia nervosa and bulimia are, as most authors believe, etiologically complex syndromes, a narrow focus on certain variables to the exclusion of others will ultimately prove to be heuristically limiting and misguided. A closer collaboration between the psychological and biomedical sciences will be needed if we are to gain further insights into these baffling and life-threatening conditions.

\section{References}

Bemis, K. M. (1978). Current approaches to the etiology and treatment of anorexia nervosa. Psychological Bulletin, 85, 593-617.

Benjamin, L. S. (1974). Structural analysis of social behavior. Psychological Review, 81, 392-425.

Beumont, P. J. V., Abraham, S. F., Argall, W. J., Gearge. G. C. W., \& Glaun, D. E. (1978). The onset of anorexia nervosa. Australian and New Zealand Journal of Psychiatry, 12, 145-149.

Biederman, J., Rivinus, T., Kemper, K., Hamilton, D., MacFadyen, J., \& Harmatz, J. (1985). Depressive disorders in relatives of anorexia nervosa patients with and without a current episode of nonbipolar major depression. American Journal of Psychiatry, 142, 1495-1496.

Bruch, H. (1973). Eating disorders: Anorexia nervosa, obesity and the person within. New York: Basic Books.

Cooper, P. J., \& Fairburn, C. G. (1983). Binge eating and self-induced vomiting in the community: A preliminary study. British Journal of Psychiatry, 142, 139-144.

Crisp, A. H. (1980). Anorexia nervosa. Let me be. New York: Grune \& Stratton.

Crisp, A. H. (1985). Nature and nurture in anorexia nervosa: A study of 34 pairs of twins, one pair of triplets, and an adoptive family. International Journal of Eating Disorders, 4, 5-28.

Crisp, A. H., Harding, B., \& McGuiness, B. (1974). Anorexia nervosa: Psychoneurotic characteristics of parents: Relationship to prognosis. Journal of Psychosomatic Research, 18, 167-173.

Crisp, A. H., Hsu, L. K. G., Harding, B., \& Hartshorn, J. (1980). Clinical features of anorexia nervosa: A study of a consecutive series of 102 female patients. Journal of Psychosomatic Research, 24, 179191.

Crisp, A. H., Palmer, R. L., \& Kalucy, R. S. (1976). How common is anorexia nervosa: A prevalence study. British Journal of Psychiatry, 128, 549-554.

Dally, P., \& Gomez, J. (1979). Anorexia nervosa. London: William Heinemann.

Garfinkel, P. E., \& Gamer, D. M. (1982). Anorexia nervosa: A multidimensional perspective. New York: Brunner/Mazel.

Garfinkel, P. E., Garner, D. M., Rose, J., Darby, P. L., Brandes, J. S., O'Hanlon, J., \& Walsh, N. (1983). A comparison of characteristics in families of patients with anorexia nervosa and normal controls. Psychological Medicine, 13, 821-828.

Garfinkel, P. E., Moldofsky, H., \& Garner, D. M. (1980). The heterogeneity of anorexia nervosa: Bulimia as a distinct subgroup. Archives of General Psychiatry, 37, 1036-1040.

Garner, D. M., Garfinkel, P. E., \& O'Shaughnessy, M. (1985). The validity of the distinction between bulimia with and without anorexia nervosa. American Journal of Psychiatry, 142, 581-587.

Gershon, E. S., Schreiber, J. L., Hamovit, J. R., Dibble, E. D., Kaye, W. H., Numberger, J. I., Andersen, A., \& Ebert, M. H. (1983). Anorexia nervosa and major affective disorders associated in families: A preliminary report. In S. B. Guze, F. J. Earls, \& J. E. Barrett (Eds.), Childhood psychopathology and development (pp. 279-284). New York: Raven Press.

Gershon, E. S., Schreiber, J. L., Hamovit, J. R., Dibble, E. D., Kaye, W. H., Nurnberger, J. I., Andersen, A., \& Ebert, M. H. (1984). Clinical findings in patients with anorexia nervosa and affective illness in their relatives. American Journal of Psychiatry, 14I, 1419-1422.

Goldstein, M. J. (1981). Family factors associated with schizophrenia and anorexia nervosa. Journal of Youth and Adolescence, 10, 385405.

Hall, A. (1978). Family structure and relationships of 50 female anorexia nervosa patients. Australian and New Zealand Journal of Psychiatry, 12, 263-268.

Halmi, K. A., Goldberg, S. C., Eckert, E., Casper, R., \& Davis, J. M. (1977). Pretreatment evaluation in anorexia nervosa. In R. A. Vigersky (Ed.), Anorexia nervosa (pp. 43-54). New York: Raven Press.

Herzog, D. B. (1982). Bulimia: The secretive syndrome. Psychosomatics, $23,481-487$.

Holland, A. J., Hall, A., Murray, R., Russell, G. F. M., \& Crisp, A. H. (1984). Anorexia nervosa: A study of 34 twin pairs. British Journal of Psychiatry, 145, 414-419.

Hsu, L. K. G., Crisp, A. H., \& Harding, B. (1979). Outcome of anorexia nervosa. Lancet, 1, 61-65.

Hudson, J. I., Pope, H. G., Jonas, J. M., \& Yurgelun-Todd, D. (1983). 
A family study of anorexia nervosa and bulimia. British Journal of Psychiatry, 142, 133-138.

Humphrey, L. L. (1986a). Family dynamics in bulimia. In S. C. Feinstein, A. H. Esman, J. G. Looney, A. Z. Schwartzberg, A. D. Sorosky, \& M. Sugar (Eds.), Annals of adolescent psychiatry: Developmental and clinical studies (Vol. 13, pp. 315-332). Chicago: University of Chicago Press.

Humphrey, L. L. (1986b). Family relations in bulimic-anorexic and nondistressed families. International Journal of Eating Disorders, 5, 223-232.

Humphrey, L. L. (1986c). Observations of family interactions among subtypes of eating disorders. Unpublished manuscript, Northwestern University.

Humphrey, L. L. (1986d). Relationships within subtypes of anorexic. bulimic, and normal families using structural analysis of social behavior. Unpublished manuscript, Northwestern University.

Humphrey, L. L. (1986e). Structural analysis of parent-child relationships in eating disorders. Journal of Abnormal Psychology, 95, 395402.

Humphrey, L. L. (1987). A comparison of bulimic-anorexic and nondistressed families using structural analysis of social behavior. Journal of the American Academy of Child Psychiatry, 26, 248-255.

Humphrey, L. L. (in press). Family-wide distress in bulimia. In D. Cannon \& T. Baker (Eds.), Addictive disorders: Psychological assessment and treatment. New York: Praeger.

Humphrey, L. L., Apple, R. F., \& Kirschenbaum, D. S. (1986). Differentiating bulimic-anorexic from normal families using interpersonal and behavioral observational systems. Journal of Consulting and Clinical Psychology, 54, 190-195.

Humphrey, L. L., \& Stern, S. (in press). Object relations and the family system in bulimia. In W. J. Johnson (Ed.), Advances in eating disorders. Greenwich, CT: JAI Press.

Johnson, C., \& Flach, A. (1985). Family characteristics of 105 patients with bulimia. American Journal of Psychiatry, 142, 1321-1324.

Kalucy, R. S., Crisp, A. H., \& Harding, B. (1977). A study of 56 families with anorexia nervosa. British Journal of Medical Psychology, 50, 381-395.

Kog, E., \& Vandereycken, W. (1985). Family characteristics of anorexia nervosa and bulimia: A reveiw of the research literature. Clinical Psychology Review, 5, 159-180.

Kog, E., Vandereycken, W., \& Vertommen, H. (1985). Towards a verifcation of the psychosomatic family model: A pilot study of ten families with an anorexia/bulimia nervosa patient. International Journal of Eating Disorders, 4, 525-538.

Kog, E., Vertommen, H., \& De Groote, T. (1986). Family interaction research in anorexia nervosa: The use and misuse of a self-report questionnaire. International Journal of Family Psychiatry, 6, 227243.

Minuchin, S., Rosman, B. L., \& Baker, L. (1978). Psychosomatic families: Anorexia nervosa in context. Cambridge, MA: Harvard University Press.

Moos, R., \& Moos, B. S. (1980). Family Environment Scale manual. Palo Alto: Consulting Psychologists Press.

Morgan, H. G., \& Russell, G. F. M. (1975). Value of family background and clinical features as predictors of long-term outcome in anorexia nervosa: Four-year follow-up study of 42 patients. Psychological Medicine. 5, 355-371.

Olson, D. H., Bell, R., \& Portner, J. (1978). Family Adaptability and Cohesion Evaluation Scale. St. Paul, MN: University of Minnesota Press.

Ordman, A. M., Kirschenbaum, D. S. (1986). Bulimia: Assessment of eating, psychological adjustment, and familial characteristics. International Journal of Eating Disorders, 5, 865-878.

Piran, N., Kennedy, S., Garfinkel, P. E., \& Owens, M. (1985). Affective disturbance in eating disorders. Journal of Nervous and Mental Disease, 173, 395-400.

Rivinus, T. M., Biederman, J., Herzog, D. B., Kemper, K., Harper, G. P., Harmatz, J. S., \& Houseworth, S. (1984). Anorexia nervosa and affective disorders: A controlled family history study. American Journal of Psychiatry, 14I, 1414-1418.

Stern, S. L., Dixon, K. N., Nemzer, E., Lake, M. D., Sansone, R. A., Smeltzer, D. J., Lantz, S., Schrier, S. S. (1984). Affective disorder in the families of women with normal weight bulimia. American Journal of Psychiatry, 141. 1224-1227.

Strober, M. (1981). The significance of bulimia in juvenile anorexia nervosa: An exploration of possible etiologic factors. International Journal of Eating Disorders, 1, 28-43.

Strober, M. (1985). Personality factors in anorexia nervosa. Pediatrician, 12, 134-138.

Strober, M., \& Katz, J. (in press). Depression in the eating disorders: A review and analysis of descriptive, family and biological factors. In D. M. Gamer \& P. E. Garfinkel (Eds.), Diagnostic issues in anorexia nervosa and bulimia nervosa. New York: Brunner/Mazel.

Strober, M., Morrell, W., Burroughs, J., Salkin, B., \& Jacobs, C. (1985). A controlled family study of anorexia nervosa. Journal of $P_{\text {sychiatric }}$ Research, 19, 239-246.

Strober, M., Salkin, B., Burroughs, J., \& Morrell, W. (1982). Validity of the bulimia-restrictor distinction in anorexia nervosa: Parental personality characteristics and family psychiatric morbidity. Journal of Nervous and Mental Disease, 170, 345-351.

Strober, M., Salkin, B., Burroughs, J., Morrell, W., Sadjak, J., Lampert, C., \& Danforth, H. (1986, May). A family study of anorexia nervosa and depression. Paper presented at the annual meeting of the American Psychiatric Association, Washington, DC.

Szmukler, G. I., Eisler, I., Russell, G. F. M., \& Dare, C. (1985). Anorexia nervosa, parental "expressed emotion," and dropping out of treatment. British Journal of Psychiatry, 147, 265-271.

Theander, S. (1970). Anorexia nervosa: A psychiatric investigation of 94 female cases. Acta Psychiatrica Scandinavica. 214 (Suppl. 214), $1-94$.

Winokur, A., March, V., \& Mendels, J. (1980). Primary affective disorder in relatives of patients with anorexia nervosa. American Journal of Psychiatry, 137, 695-698.

Yager, J., \& Strober, M. (1985). Family aspects of eating disorders. In A. Frances \& R. Hales (Eds.), Psychiatric update-IV (pp. 481-502). Washington, DC: American Psychiatric Press.

Received March 4, 1987

Revision received March 16, 1987

Accepted March 16,1987 